\title{
Surgical outcomes of the Ex-PRESS glaucoma filtration device in African American and white glaucoma patients
}

This article was published in the following Dove Press journal:

Clinical Ophthalmology

21 June 2012

Number of times this article has been viewed

\author{
Sarwat Salim \\ Haiming Du \\ Sumalee Boonyaleephan \\ Jim Wan
}

University of Tennessee Health

Science Center, Memphis, TN, USA
Correspondence: Sarwat Salim Associate Professor of Ophthalmology, Hamilton Eye Institute, 930 Madison Avenue, Suite 470, Memphis,

TN 38163, USA

$\mathrm{Tel}+\mathrm{I}$ 90I 4485883

Fax +I 90I 448 I260

Email ssalim@uthsc.edu
Purpose: To compare the surgical outcomes of the Ex-PRESS glaucoma filtration device in African American and white glaucoma patients.

Design: Retrospective comparative case series.

Methods: This was a comparative case series of 36 eyes of 36 African Americans and 43 eyes of 43 whites that underwent placement of the Ex-PRESS glaucoma filtration device under a partialthickness scleral flap for uncontrolled glaucoma. All eyes received intraoperative mitomycin C. The primary outcome measures were intraocular pressure (IOP), number of postoperative glaucoma medications, and surgical success. Surgical success was defined as IOP between 5 and $18 \mathrm{~mm} \mathrm{Hg}$, with or without glaucoma medications, without further glaucoma surgery, or loss of light perception vision.

Results: Average follow-up was $31.9 \pm 9.8$ (range, 14.6-47) months for African Americans and $30.7 \pm 8.6$ (range, 14.3-47) months for whites. At 33 months, surgical success was $80.0 \%$ in the African American group and $83.3 \%$ in the white group $(\mathrm{P}=1.00)$. Reasons for surgical failure included increased IOP ( 3 eyes, 3.8\%), persistent hypotony with maculopathy (1 eye, $1.3 \%$ ), and further surgery ( 4 eyes, $5.06 \%$ ). Compared with preoperative values, the mean postoperative IOP and number of glaucoma medications were significantly reduced in both groups, and no statistical difference was observed between the two groups at 33 months. Postoperative complications were similar in the two groups.

Conclusions: Similar surgical outcomes were observed in African American and white glaucoma patients after implantation of the Ex-PRESS glaucoma filtration device. This latest modification of glaucoma filtration surgery may be a better surgical option for African Americans given its potential advantages of no tissue removal, predictable outcomes related to consistent lumen size and controlled flow, fewer postoperative complications, and overall reduced inflammation.

Keywords: glaucoma, trabeculectomy, Ex-PRESS glaucoma filtration device, antimetabolites, African American, White

\section{Introduction}

Glaucoma continues to be a major public health challenge as one of the leading causes of blindness worldwide. ${ }^{1}$ Compared with white populations, glaucoma presents earlier, progresses more rapidly, and is associated with a higher incidence of blindness in African Americans. ${ }^{2-6}$ Furthermore, treatment outcomes have been reported to vary in African American and white patients. ${ }^{7-9}$

Glaucoma filtration surgery remains the most effective surgical procedure for uncontrolled glaucoma. ${ }^{10}$ In black patients, glaucoma filtration surgery has been reported to have lower surgical success compared to white patients, presumably due 
to a more exuberant inflammatory response. ${ }^{10-13}$ The use of antifibrosis agents with glaucoma filtration surgery has been reported to improve surgical outcomes in African Americans. ${ }^{14-17}$

One of the recent modifications of glaucoma filtration surgery has been the placement of the Ex-PRESS glaucoma filtration device (Alcon, Fort Worth, TX) under a partialthickness scleral flap. ${ }^{18}$ The Ex-PRESS glaucoma filtration device is a biocompatible, magnetic resonance imagingcompatible, stainless steel, nonvalved device that diverts aqueous humor from the anterior chamber to the subconjunctival space and forms a traditional filtration bleb, as seen in standard trabeculectomy. ${ }^{19,20}$

The aim of our study was to evaluate the surgical outcomes of the Ex-PRESS glaucoma filtration device placed under a partial-thickness scleral flap with intraoperative application of mitomycin C (MMC) in African American and white patients. Unlike conventional trabeculectomy, sclerectomy and iridectomy are not performed with the Ex-PRESS glaucoma filtration device. Therefore, less inflammation is encountered with this procedure both intraoperatively and postoperatively. We hypothesized that these modifications may enhance surgical outcomes in black patients.

\section{Methods}

This was a single-center, retrospective comparative study of eyes treated with the Ex-PRESS glaucoma filtration device under a partial-thickness scleral flap in African American and white glaucoma patients. The study protocol was approved by the Institutional Review Board, and informed consent was obtained before surgery. All surgeries were performed by one surgeon (SS). All patients requiring surgical intervention were on maximum tolerated medical therapy and were judged to require additional intraocular pressure (IOP) reduction to prevent further progression of glaucomatous optic neuropathy and associated visual field loss. Exclusion criteria included previous standard trabeculectomy and combined cataract and Ex-PRESS glaucoma filtration device.

All surgeries were performed under inferonasal subTenon local anesthesia. A 6-0 polyglactin suture (Vicryl; Ethicon, San Angelo, TX) was passed in the cornea superiorly to infraduct the eye. A fornix-based conjunctival flap was incised in all cases. Cautery was used when necessary to achieve hemostasis on the scleral bed. MMC $(0.4 \mathrm{mg} / \mathrm{mL})$ was applied before formation of the scleral flap for 1-3 minutes' duration depending on the patient's underlying conjunctival characteristics, such as hyperemia or thinning. After removing the sponges, the site was irrigated copiously with balanced salt solution. A partial-thickness triangular scleral flap was outlined with a $15^{\circ}$ blade and elevated with a $57^{\circ}$ blade. A 25 -gauge needle was used to enter the anterior chamber slightly posterior to the blue-gray zone under the scleral flap, and the Ex-PRESS device (model P50) was introduced into the anterior chamber through the needle track by using a disposable delivery system. The scleral flap was sutured with interrupted 10-0 nylon sutures, adjusting the tension on the sutures to maintain anterior chamber depth with slow flow of aqueous humor around the margins of the scleral flap. The conjunctiva was closed with interrupted wing sutures at both ends of the incision. A subconjunctival injection of steroid and antibiotic was given in the inferior fornix, and the corneal traction suture was removed. The eye was dressed with antibiotic and steroid ointment or solution, a light gauze dressing, and an eye shield. Topical antibiotic (fourth-generation fluoroquinolone) and steroid, generally prednisolone acetate $1 \%$, were given postoperatively and tapered over several weeks.

Preoperative information included patient age, sex, race, glaucoma diagnosis, history of laser, glaucoma medications, IOP measured by Goldmann applanation tonometer, and visual acuity. In terms of glaucoma diagnosis, combinedmechanism glaucoma was designated for patients who had both open and closed components of the drainage angle and had required laser peripheral iridotomy in the past. Mixed-mechanism glaucoma was reserved for patients where a combination of multiple surgeries, inflammation, steroid use, or bleeding may have contributed to the underlying mechanism. The primary outcome measures were IOP, number of postoperative glaucoma medications, and surgical success. Surgical success was defined as IOP between 5 and $18 \mathrm{mmHg}$, with or without glaucoma medications, without further glaucoma surgery, or loss of light-perception vision. Laser suture lysis was not considered a failure of the procedure and performed at the discretion of the surgeon depending on the clinical situation. Postoperative complications, including hyphema, choroidal effusions, flat anterior chamber, hypotony, bleb leak, suprachoroidal hemorrhage, endophthalmitis, and device-related complications were assessed. Bleb leak was considered a complication during the late postoperative period (more than 6 weeks after surgery), and early hypotony was defined as IOP $<5 \mathrm{mmHg}$ during the first postoperative week.

The two groups were compared using the two-sample $t$-test and Mann-Whitney test for continuous variables, and Pearson's $\chi^{2}$ and Fisher's exact tests for categorical data. Since the two-sample $t$-test and Mann-Whitney test 
gave similar results, only results from the $t$-test are reported here. Success rates in both groups were compared using Kaplan-Meier life-table analysis and the log-rank test. Differences were considered statistically significant at a $P$-value of 0.05 or less. All analyses were done using SAS 9.2 software (SAS Institute, Cary, NC).

\section{Results}

The Ex-PRESS glaucoma filtration device was inserted in 36 eyes of 36 African Americans and 43 eyes of 43 Caucasians. The mean follow-up was $31.9 \pm 9.8$ (range 14.6-47) months for African Americans and $30.7 \pm 8.6$ (range 14.3-47) months for whites. The baseline characteristics of the two groups are shown in Table 1. There was no difference between the two groups in terms of age, sex, baseline IOP, preoperative glaucoma medications, or type of glaucoma.

A significant reduction in IOP occurred at all time points in both groups compared to baseline IOP, and no significant difference in IOP lowering was noted between the two groups (Table 2). The mean IOP before and after insertion of the Ex-PRESS device is shown in Figure 1. The preoperative IOP for each eye was determined by an average of two

Table I Preoperative characteristics for African American and white glaucoma patients

\begin{tabular}{|c|c|c|c|}
\hline & $\begin{array}{l}\text { African Americans } \\
n=36 \text { eyes } \\
36 \text { patients }\end{array}$ & $\begin{array}{l}\text { White } \\
n=43 \text { eyes } \\
43 \text { patients }\end{array}$ & $P$-value \\
\hline $\begin{array}{l}\text { Age (years) } \\
(\text { mean } \pm S D)\end{array}$ & $66.1 \pm 11.3$ & $70.1 \pm 12.4$ & 0.1431 \\
\hline Sex & & & 0.4694 \\
\hline Male & 18 & 18 & \\
\hline Female & 18 & 25 & \\
\hline Eye (OD/OS) & $20 / 16$ & $21 / 22$ & 0.5517 \\
\hline Previous lasers & & & 0.5250 \\
\hline None & 28 & 27 & \\
\hline ALT & 4 & 10 & \\
\hline SLT & I & 2 & \\
\hline LPI & 3 & 4 & \\
\hline $\begin{array}{l}\text { Glaucoma medications } \\
\text { (mean } \pm S D)\end{array}$ & $2.8 \pm 0.5$ & $2.8 \pm 0.5$ & 0.9423 \\
\hline $\begin{array}{l}\text { Baseline IOP }(\mathrm{mmHg}) \\
(\text { mean } \pm \mathrm{SD})\end{array}$ & $23.8 \pm 9.1$ & $23.0 \pm 10.0$ & 0.7178 \\
\hline Type of glaucoma & & & 0.3951 \\
\hline Primary open angle & 25 & 26 & \\
\hline Low tension & 0 & 5 & \\
\hline Combined mechanism & 5 & 3 & \\
\hline Exfoliation & I & 2 & \\
\hline Pigmentary & 0 & I & \\
\hline Mixed mechanism & 5 & 6 & \\
\hline
\end{tabular}

Abbreviations: LPI, laser peripheral iridotomy; ALT, argon laser trabeculoplasty SLT, selective laser trabeculoplasty; SD, standard deviation; IOP, intraocular pressure.
Table 2 Change from baseline intraocular pressure $(\mathrm{mmHg})$ in eyes treated with Ex-PRESS in African Americans and whites (mean \pm standard deviation)

\begin{tabular}{|c|c|c|c|}
\hline $\begin{array}{l}\text { Postoperative } \\
\text { time } \\
\end{array}$ & $\begin{array}{l}\text { African Americans } \\
(\mathrm{n}=36)\end{array}$ & $\begin{array}{l}\text { White } \\
(n=43)\end{array}$ & $P$-value \\
\hline I day & $-11.4 \pm 11.2$ & $-11.1 \pm 13.1$ & 0.9140 \\
\hline 7 days & $-8.7 \pm 12.6$ & $-13.0 \pm 11.0$ & 0.1123 \\
\hline I month & $-11.1 \pm 10.2$ & $-10.2 \pm 10.1$ & 0.6923 \\
\hline 3 months & $-9.5 \pm 9.3$ & $-12.2 \pm 10.6$ & 0.2646 \\
\hline 6 months & $-7.4 \pm 9.5$ & $-12.6 \pm 11.1$ & 0.0577 \\
\hline 9 months & $-9.7 \pm 8.7$ & $-9.6 \pm 12.4$ & 0.9854 \\
\hline 12 months & $-9.0 \pm 8.3$ & $-\mid I . I \pm 12.8$ & 0.5653 \\
\hline 15 months & $-10.2 \pm 8.6$ & $-11.0 \pm 10.7$ & $0.837 I$ \\
\hline 18 months & $-9.5 \pm 9.8$ & $-8.1 \pm 11.9$ & 0.7528 \\
\hline 21 months & $-10.5 \pm 7.8$ & $-14.6 \pm 16.3$ & 0.5318 \\
\hline 24 months & $-10.6 \pm 9.8$ & $-13.4 \pm 12.7$ & 0.6537 \\
\hline 27 months & $-7.1 \pm 10.0$ & $-6.1 \pm 9.4$ & 0.8743 \\
\hline 30 months & $-12.4 \pm 7.5$ & $-13.4 \pm 18.1$ & 0.9219 \\
\hline 33 months & $-13.8 \pm 9.7$ & $-17.2 \pm 20.1$ & 0.8088 \\
\hline 36 months & $-11 \pm 0$ & $-26.5 \pm 20.5$ & 0.6480 \\
\hline
\end{tabular}

IOP measurements from previous consecutive visits before surgical intervention. The mean \pm standard deviation (SD) preoperative IOP was $23.8 \pm 9.1$ for the African American group and $23.0 \pm 10.0$ for the Caucasian group $(P=0.72)$. The mean IOP postoperatively was significantly lower in both groups compared with baseline IOP at all time points. The mean IOP was higher in the African American group when compared with the white group at day 7 , month 3 , and month 6 with $P \leq 0.05$. The mean postoperative IOP was not statistically different between the two groups at 1 year (13.9 vs $12.2 ; P=0.39)$, 2 years ( 12.9 vs $10.7 ; P=0.72)$, and 33 months (11.0 vs $11.3 ; P=0.92)$. These values have been summarized in Table 3 .

The mean number of glaucoma medications preoperatively and postoperatively is shown in Figure 2. At baseline, the mean \pm SD baseline or preoperative glaucoma medications was $2.8 \pm 0.5$ in each group. There was a significant reduction seen in the number of postoperative glaucoma medications required in both groups compared with baseline medications. The mean number of postoperative medications was higher in the African American group when compared with the white group at months 18 and 27. The mean number of postoperative medications was not statistically different for the two groups at year $1(0.56$ vs $0.21 ; P=0.07)$, year 2 ( 0.31 vs $0.10 ; P=0.24)$, and 33 months ( 0.0 vs 0.05 ; $P=0.42$ ). These values have been summarized in Table 3 .

The survival analysis is shown in Figure 3, with a success rate of $80.0 \%$ in the African American group and $83.3 \%$ in the white group at 33 months. The survival curves for 


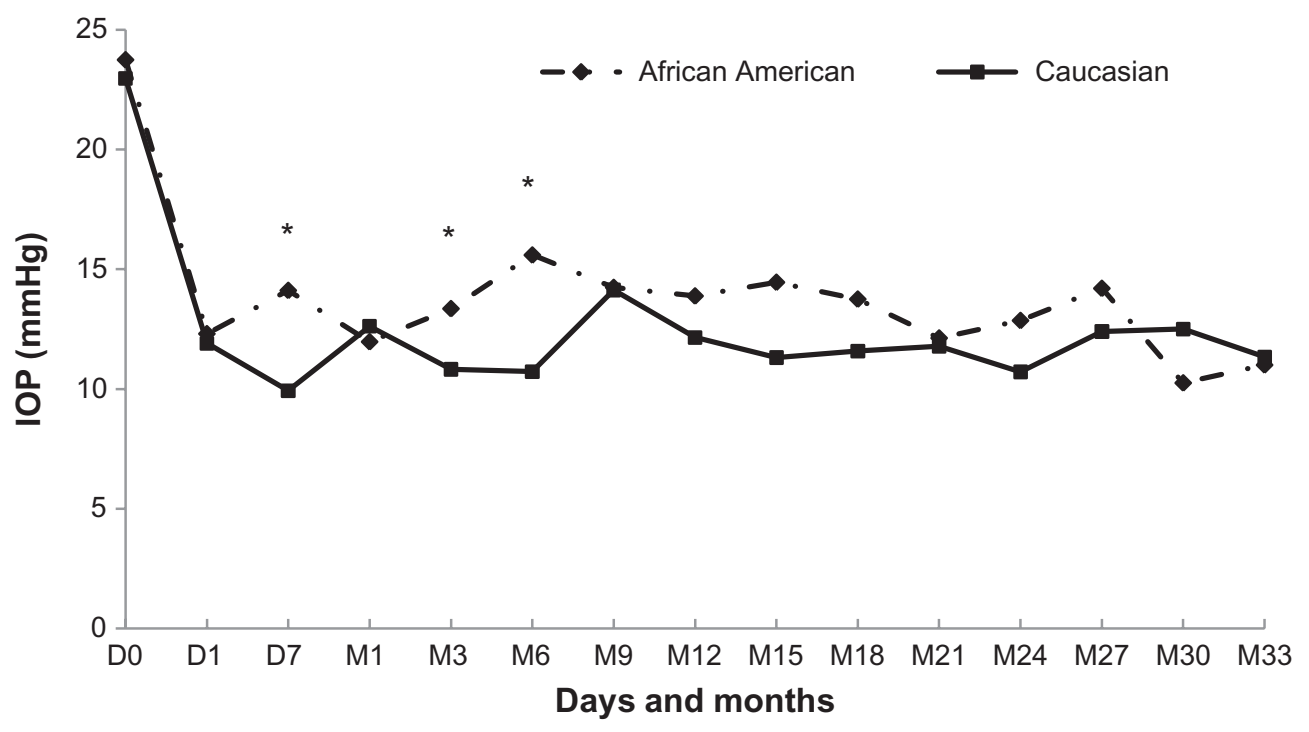

Figure I Mean intraocular pressure (IOP) after implantation of Ex-PRESS in African Americans and whites. Note: $* P \leq 0.05$.

the two groups were not significantly different $(P=1.00)$. Reasons for surgical failure included increased IOP (three eyes, $3.8 \%$ ), persistent hypotony with maculopathy (one eye, $1.3 \%$ ), and further surgery (four eyes, 5.06\%). Three patients had high IOP of 33, 31, and $20 \mathrm{mmHg}$ at 6, 9, and 6 months after surgery, respectively. All three patients required additional surgery with a glaucoma drainage implant. One patient had persistent hypotony and underwent bleb revision. No eyes had loss of light-perception vision.

There were no intraoperative complications in either group. Postoperative complications were similar in both groups (Table 3). Hyphema was observed more in white

Table 3 Mean intraocular and glaucoma medications in African Americans and Caucasians at all follow-up visits

\begin{tabular}{|c|c|c|c|c|}
\hline \multirow[t]{3}{*}{ Time } & \multicolumn{2}{|c|}{ Intraocular pressure } & \multicolumn{2}{|c|}{ Glaucoma medications } \\
\hline & African & Caucasian & African & Caucasian \\
\hline & American & & American & \\
\hline I day & 23.75 & 22.97 & 2.81 & 2.81 \\
\hline 7 days & $|2.3|$ & 11.90 & 0.00 & 0.00 \\
\hline I month & |4.1| & 9.93 & 0.08 & 0.00 \\
\hline 3 months & II.97 & 12.62 & 0.08 & 0.05 \\
\hline 6 months & 13.35 & 10.82 & 0.33 & 0.21 \\
\hline 9 months & 15.59 & 10.72 & 0.72 & 0.28 \\
\hline 12 months & 14.24 & 14.13 & 0.58 & 0.23 \\
\hline 15 months & 13.88 & 12.15 & 0.56 & 0.21 \\
\hline 18 months & 14.45 & II.31 & 0.35 & 0.20 \\
\hline 21 months & 13.75 & II.58 & 0.55 & 0.14 \\
\hline 24 months & 12.13 & II.78 & 0.17 & 0.09 \\
\hline 27 months & 12.86 & 10.71 & 0.31 & 0.10 \\
\hline 30 months & 14.20 & 12.40 & 0.42 & 0.04 \\
\hline 33 months & 10.25 & 12.50 & 0.10 & 0.04 \\
\hline 36 months & 11.00 & 11.33 & 0.00 & 0.05 \\
\hline
\end{tabular}

eyes, and choroidal effusions were more frequent in African American eyes, but these differences were not statistically significant. One white patient developed hypotony maculopathy. One patient in each group had lateonset bleb leak, which resolved with conservative therapy. One patient in each group had a blocked device that was successfully treated with an Nd:YAG laser, resulting in liberation of fibrinous material at the tip of the Ex-PRESS device with restoration of aqueous outflow. Eyes requiring laser suture lysis were similar in the African American and white groups ( $42 \%$ vs $33 \%$, respectively; $P=0.40)$. Early hypotony was also similar in the two groups $(8 \%$ vs $12 \% ; P=0.72)$.

\section{Discussion}

Multiple studies have reported racial differences between blacks and whites in response to medical, laser, or surgical therapy for glaucoma. The varied responses in African Americans have been attributed to iris pigmentation, corneal thickness, number of preoperative glaucoma medications, cellular profile of the conjunctiva, more exuberant healing response to surgery, and socioeconomic factors. ${ }^{21-25}$

The most notable study that evaluated the differences in treatment outcomes between black and white patients was the Advanced Glaucoma Intervention Study (AGIS). ${ }^{7-9}$ Patients were randomized to a treatment sequence of argon laser trabeculoplasty $\rightarrow$ trabeculectomy $\rightarrow$ trabeculectomy (ATT sequence) or trabeculectomy $\rightarrow$ argon laser trabeculoplasty $\rightarrow$ trabeculectomy (TAT sequence). The main outcome measures were visual acuity and visual field, although IOP, 


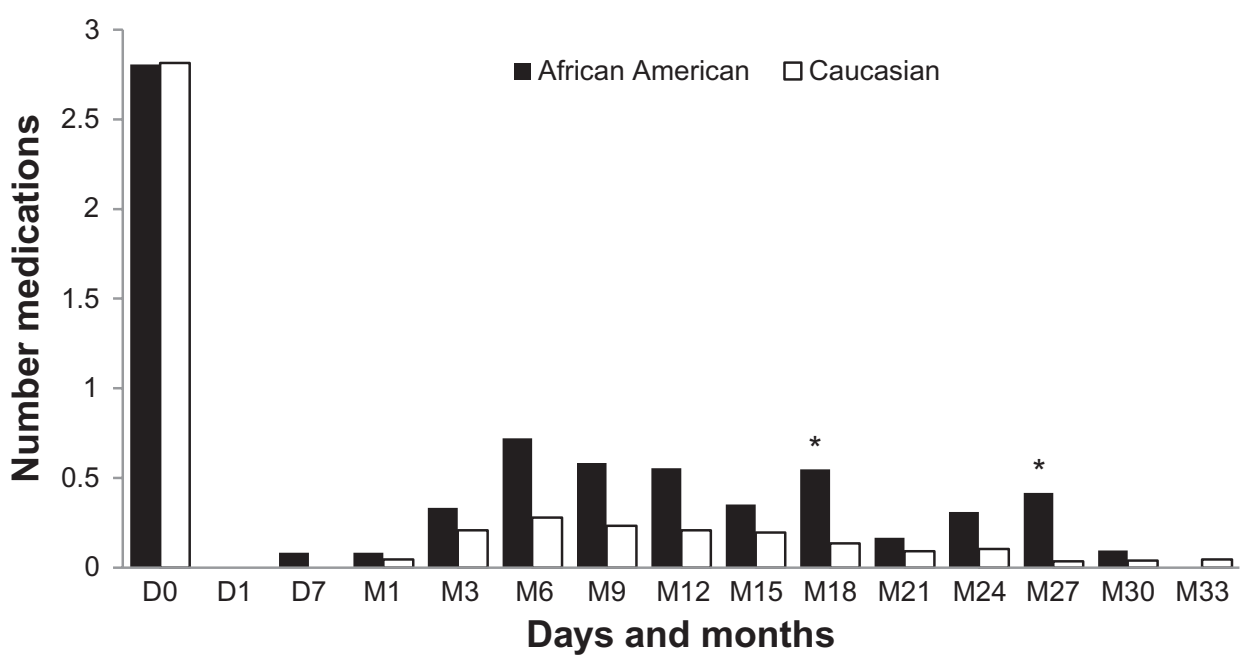

Figure 2 Mean number of glaucoma medications after implantation of Ex-PRESS in African Americans and whites. Note: $* P \leq 0.05$.

complication rates, and need for adjunctive medications were evaluated as well. Racial differences were reported in the treatment outcomes in white and black patients between the randomized groups at 7-10 years of follow-up. ${ }^{7,9}$ The results favored the ATT sequence in black patients and the TAT sequence in white patients, based on preservation of visual function.

In addition to race-specific analysis between the two randomized intervention sequences as described above, further analysis was conducted to determine whether the treatmentspecific clinical course of glaucoma differs between eyes of white and black patients. ${ }^{8}$ After baseline differences were adjusted, blacks had lower failure rates with argon laser trabeculoplasty than did whites in the ATT sequence. This finding conflicted with results of previous laser studies, which demonstrated either higher failure rates in blacks

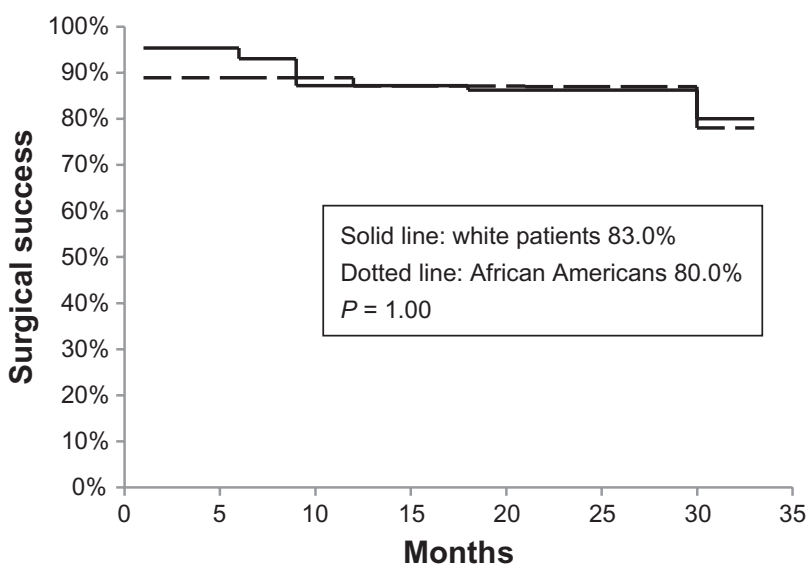

Figure 3 Kaplan-Meier survival analysis after implantation of Ex-PRESS glaucoma filtration device in African American and white glaucoma patients. or equivalent results between blacks and whites. ${ }^{26,27}$ In the TAT sequence, blacks had higher failure rates with initial trabeculectomy, and these findings were consistent with previously reported trabeculectomy outcomes in blacks. ${ }^{7,28,29} \mathrm{Of}$ note, most initial trabeculectomies in AGIS were performed without antifibrosis agents. Since adjunctive use of antimetabolites has been reported to improve surgical outcomes of trabeculectomy in blacks, it is possible that extensive use of antimetabolites might have improved the outcomes of trabeculectomy in blacks and enhanced the beneficial effects of trabeculectomy in whites. In the present study, MMC was used intraoperatively in all eyes.

The Ex-PRESS glaucoma filtration device is one of the newest modifications of glaucoma filtration surgery. The device is inserted under a partial-thickness scleral flap into the anterior chamber through a needle track created by a 23- or 25-gauge needle. Unlike standard trabeculectomy, sclerectomy and iridectomy are not performed at the time of surgery, minimizing both intraoperative and postoperative inflammation. Also, variations in the fistula size seen

Table 4 Postoperative complications after Ex-PRESS in African American and white glaucoma patients

\begin{tabular}{llll}
\hline Complications & $\begin{array}{l}\text { African Americans } \\
(\mathbf{n}=\mathbf{3 6}) \\
\mathbf{n} \text { and \% }\end{array}$ & $\begin{array}{l}\text { White } \\
\mathbf{( n = 4 3 )} \\
\mathbf{n} \text { and \% }\end{array}$ & P-value \\
\hline Hyphema & $0(0)$ & $3(8)$ & 0.2559 \\
Choroidal effusions & $6(18)$ & $2(5)$ & $0.141 \mathrm{I}$ \\
$\begin{array}{l}\text { Hypotony maculopathy } \\
\text { Late bleb leak (more than }\end{array}$ & $0(0)$ & $\mathrm{I}(3)$ & 1.0000 \\
6 weeks after surgery) & & $\mathrm{I}(3)$ & 1.0000 \\
Blocked device & $\mathrm{I}(3)$ & $\mathrm{I}(3)$ & 1.0000 \\
\hline
\end{tabular}


with traditional trabeculectomy are avoided, minimizing unpredictable outcomes and adverse side effects.

Several retrospective and prospective studies have compared the safety and efficacy of the Ex-PRESS device under a scleral flap with standard trabeculectomy and have reported similar or better IOP outcomes. ${ }^{30-32}$ Many of these studies have demonstrated superiority of this technique over standard trabeculectomy in reducing intraoperative and postoperative complications due to a more controlled outflow of aqueous humor through consistent lumen size. In addition, rapid visual recovery secondary to less inflammation and fewer postoperative visits were reported in one retrospective study. ${ }^{32}$ In AGIS 11, analysis of risk factors for failure of trabeculectomy and argon laser trabeculoplasty demonstrated that marked postoperative inflammation increased the risk of trabeculectomy failure by $160 \%$ (hazard ratio $=2.60$ ). ${ }^{33}$ In the present study, similar surgical success was achieved in both races, presumably from no tissue removal and subsequently less inflammation with the Ex-PRESS filtration device.

In addition to inflammation related to surgical technique, other risk factors have been described for failure of glaucoma filtration surgery. ${ }^{24,25,34,35}$ A thicker Tenon's capsule at the time of surgery or its ability to incite greater inflammatory reaction after surgical trauma was reported to be a risk factor of filtration surgery in blacks, and its removal has been suggested by some investigators. ${ }^{36,37}$ However, in one comparative study of trabeculectomy with and without tenonectomy, no statistically significant difference was noted in the two studied groups. ${ }^{38}$ Differences in conjunctival cell population have been reported in blacks and whites. ${ }^{24}$ The conjunctival biopsy specimens from blacks demonstrated more fibroblasts and macrophages compared to those from whites. Since fibroblasts are typically responsible for wound healing, the amplified macrophage activity may result in exaggerated wound healing and may partially explain more surgical failures among black patients. In addition to the cell numbers, variations in cell activation and function have also been postulated to be responsible for the differences observed. Different degrees of postoperative hyperemia and aqueous humor composition have also been proposed as potential risk factors for filtration surgery in blacks when compared to whites. ${ }^{39,40}$ In one Ex-PRESS study, evaluation by the Moorfields bleb-grading system demonstrated consistently less vascularity in Ex-PRESS blebs compared to standard trabeculectomy blebs; however, these differences were absent at study completion. ${ }^{32}$

In addition, the number of preoperative medications may influence surgical success after glaucoma filtration surgery. ${ }^{25,41}$ Since glaucoma assumes a more aggressive course in African Americans, more medications preoperatively may adversely affect surgical outcomes. Goblet cell population has been reported to be reduced in eyes with long-term use of glaucoma medications. ${ }^{42}$ Although it remains unclear whether fewer goblet cells could incite a more exuberant healing response in blacks, further evaluation is warranted to understand the adverse effect of glaucoma medications on goblet cells in black and white patients. In fact, better results of trabeculectomy were seen in blacks when trabeculectomy was the primary procedure rather than secondary intervention after failure of medical therapy. ${ }^{43}$ In AGIS, black patients were also found to be on more glaucoma medications preoperatively than were white patients in both treatment sequences. In the current study, the number of preoperative glaucoma medications in the two groups was similar.

Limitations of the current study include its retrospective design with potential for selection bias, modest sample size, and short follow-up time. More failures can be expected with longer follow-up. We also acknowledge that MMC application, ranging from 1 to 3 minutes, may have introduced some variability in our results. The application time of MMC varied depending on conjunctival hyperemia or overall health of the conjunctiva. Unlike many other studies, all cases in our study were done by a single surgeon, controlling some of the confounding factors, such as clinical indications for surgery and surgical technique. The results of this retrospective study merit further evaluation of race influence on outcomes of Ex-PRESS glaucoma filtration device in a longitudinal, prospective, randomized study.

In summary, our results suggest that insertion of the Ex-PRESS glaucoma filtration device augmented by antimetabolite use may be a better surgical option for African Americans, given its potential advantages of no tissue removal with reduced inflammation and predictable outcomes related to consistent lumen size and controlled flow that may reduce postoperative complications and overall failure rates. An exaggerated healing response in blacks after glaucoma filtration surgery is known to be a major risk factor for surgical failure. Whether it is due to a thick Tenon's capsule, reduced goblet cells, amplified macrophages and fibroblasts, or excessive inflammation from these or other unknown factors, additional research is needed to explore these possibilities. While the inherent characteristics of the conjunctiva cannot be changed, modifications in surgical technique of glaucoma filtration surgery may improve outcomes in blacks. 


\section{Acknowledgment}

Presented in part at the Association for Research in Vision and Ophthalmology Annual Meeting, Fort Lauderdale, FL, May 8, 2012.

\section{Disclosure}

Dr. Salim is a lecturer for Alcon Laboratories, Fort Worth, TX, USA

\section{References}

1. Quigley HA. Number of people with glaucoma worldwide. $\mathrm{Br} J$ Ophthalmol. 1996;80:389-393.

2. Wilensky JT, Gandhi N, Pan T. Racial influences in open-angle glaucoma. Ann Ophthalmol. 1978;10:1398-1402.

3. Quigley HA, Vitale S. Models of open-angle glaucoma prevalence and incidence in the United States. Invest Ophthalmol Vis Sci. 1997;38: 83-91.

4. Quigley HA, Tielsch JM, Katz J, et al. Rate of progression in openangle glaucoma estimated from cross-sectional prevalence of visual field damage. Am J Ophthalmol. 1996;122:355-363.

5. Musch DC, Lichter PR, Guine KE, et al. The Collaborative Initial Glaucoma Treatment Study. Ophthalmology. 1999;106:653-662.

6. Wilson MR, Kosoko O, Cowan CL Jr, et al. Progression of visual field loss in untreated glaucoma patients and glaucoma suspects in St Lucia West Indies. Am J Ophthalmol. 2002;134:399-405.

7. The AGIS Investigators. The Advanced Glaucoma Intervention Study (AGIS): 4. Comparison of treatment outcomes within race. Seven-year results. Ophthalmology. 1998;105(7):1146-1164.

8. The AGIS Investigators. The Advanced Glaucoma Intervention Study (AGIS): 9. Comparison of glaucoma outcomes in black and white patients within treatment groups. Am J Ophthalmol. 2001;132(3): 311-320.

9. The AGIS Investigators. The Advanced Glaucoma Intervention Study (AGIS): 13. Comparison of treatment outcomes within race: 10-year results. Ophthalmology. 2004;111:651-664.

10. Husain R, Clarke JCK, Seah SKL, et al. A review of trabeculectomy in East Asian people - the influence of race. Eye. 2005;19:243-252.

11. Welsh NH. Failure of filtration operations in the African. $\mathrm{Br} J$ Ophthalmol. 1970;54:594-598.

12. Merritt JC. Filtering procedures in American blacks. Ophthalmic Surg. 1980;11:91-94.

13. Kim HY, Egbert PR, Singh K. Long-term comparison of primary trabeculectomy with 5-fluorouracil versus mitomycin C in West Africa. J Glaucoma. 2008;17:578-583.

14. Singh K, Egbert PR, Byrd S, et al. Trabeculectomy with intraoperative 5-fluorouracil vs mitomycin C. Am J Ophthalmol. 1997;123:48-53.

15. Mermoud A, Salmon JF, Murray AD. Trabeculectomy with mitomycin C for refractory glaucoma in blacks. Am J Ophthalmol. 1993;116:72-78

16. Egbert PR, Williams AS, Singh K, et al. A prospective trial of intraoperative fluorouracil during trabeculectomy in a black population. $\mathrm{Am} \mathrm{J}$ Ophthalmol. 1993;116:612-616.

17. Mwanza JC, Kabasele PM. Trabeculectomy with and without mitomycin $\mathrm{C}$ in a black African population. Eur $J$ Ophthalmol. 2001;11(3):261-263.

18. Dahan E, Carmichael TR. Implantation of a miniature glaucoma device under a scleral flap. J Glaucoma. 2005;14:98-102.

19. Nyska A, Glovinsky Y, Belkin M, et al. Biocompatibility of the Ex-PRESS miniature glaucoma drainage implant. J Glaucoma. $2003 ; 12: 275-280$.
20. Geffen N, Trope GE, Alasbali T, et al. Is the Ex-PRESS glaucoma shunt magnetic resonance imaging safe? J Glaucoma. 2010;19:116-118.

21. Katz IM, Berger ET. Effects of iris pigmentation on response of ocular pressure to timolol. Surv Ophthalmol. 1979;23:395-398.

22. Netland PA, Robertson SM, Sullivan EK, et al. Response to travoprost in black and nonblack patients with open-angle glaucoma or ocular hypertension. Adv Ther. 2003;20:149-163.

23. Shimmyo M, Ross AJ, Moy A, et al. Intraocular pressure, Goldmann applanation tension, corneal thickness, and corneal curvature in whites, Asians, Hispanics, and African Americans. Am J Ophthalmol. 2003;136:603-613.

24. Broadway D, Grierson I, Hitchings R. Racial differences in the results of glaucoma filtration surgery: are racial differences in the conjunctival cell profile important? Br J Ophthalmol. 1994;78:466-475.

25. Lavin MJ, Wormaid RPL, Migdal CS, et al. The influence of prior therapy on the success of trabeculectomy. Arch Ophthalmol. 1990;108:1543-1548.

26. Schwartz AL, Love DC, Schwartz MA. Long-term follow-up of argon laser trabeculoplasty for uncontrolled open-angle glaucoma. Arch Ophthalmol. 1985;103:1482-1484.

27. Krupin T, Patkin R, Kurata FK, et al. Argon laser trabeculoplasty in black and white patients with open-angle glaucoma. Ophthalmology. 1986;93:811-816.

28. Shingleton BJ, Distler JA, Baker BH. Filtration surgery in black patients: early results in a West Indian population. Ophthalmic Surg. 1987; 18:195-199.

29. Scott IU, Greenfield DS, Schiffman J, et al. Outcomes of primary trabeculectomy with the use of adjunctive mitomycin. Arch Ophthalmol. 1998;116:286-291.

30. Maris PJ, Ishida K, Netland PA. Comparison of trabeculectomy with Ex-PRESS miniature glaucoma device implanted under scleral flap. J Glaucoma. 2007;16:14-19.

31. de Jong LA. The Ex-PRESS glaucoma shunt versus trabeculectomy in open-angle glaucoma: a prospective randomized study. Adv Ther. 2009;26:336-345.

32. Good TJ, Kahook MY. Assessment of bleb morphologic features and postoperative outcomes after Ex-PRESS drainage device implantation versus trabeculectomy. Am J Ophthalmol. 2011;151(3):507-513.

33. The AGIS Investigators. The Advanced Glaucoma Intervention Study (AGIS): 11. Risk factors for failure of trabeculectomy and argon laser trabeculoplasty. Am J Ophthalmol. 2002;134:481-498.

34. Gressel MG, Heuer DK, Parrish RK. Trabeculectomy in young patients. Ophthalmology. 1984;91:1242-1246.

35. Heuer DK, Gressel MG, Parrish RK, et al. Trabeculectomy in aphakic eyes. Ophthalmology. 1984;91:1045-1051.

36. Welsh NH. Failure of filtration operations in the African. $\mathrm{Br} J$ Ophthalmol. 1970;54:594-598.

37. Kietzman B. Glaucoma surgery in Nigerian eyes: a five-year study. Ophthalmic Surg. 1976;7:52-58.

38. Kapetansky EM. Trabeculectomy, or trabeculectomy plus tenonectomy: a comparative study. Glaucoma. 1980;2:451-453.

39. Berardesca E, Maiback HI. Cutaneous reactive hyperemia: racial differences induced by corticoid application. Br J Dermatol. 1989;120: 787-794.

40. Herschler J, Litin BS. Biochemical abnormalities in the aqueous in chronic-angle glaucoma. Ophthalmic Surg. 1987;18:792-795.

41. Broadway C, Grierson I, O'Brien C, Hitchings RA. Adverse effects of topical antiglaucoma medication. II. The outcome of filtration surgery. Arch Ophthalmol. 1994;112:1446-1454.

42. Sherwood MB, Grierson I, Millar L, et al. Long-term morphologic effects of antiglaucoma drugs on the conjunctiva and Tenon's capsule in glaucomatous patients. Ophthalmology. 1989;96:327-335.

43. Wilson MR. Posterior lip sclerectomy vs trabeculectomy in West Indian blacks. Arch Ophthalmol. 1989;107:1604-1608. 


\section{Publish your work in this journal}

Clinical Ophthalmology is an international, peer-reviewed journal covering all subspecialties within ophthalmology. Key topics include: Optometry; Visual science; Pharmacology and drug therapy in eye diseases; Basic Sciences; Primary and Secondary eye care; Patient Safety and Quality of Care Improvements. This journal is indexed on
PubMed Central and CAS, and is the official journal of The Society of Clinical Ophthalmology (SCO). The manuscript management system is completely online and includes a very quick and fair peer-review system, which is all easy to use. Visit http://www.dovepress.com/ testimonials.php to read real quotes from published authors. 